\title{
The Contegra conduit in the right ventricular outflow tract induces supravalvular stenosis
}

Bart Meyns, MD, $\mathrm{PhD}^{\mathrm{a}}$

Leen Van Garsse, MD ${ }^{\mathrm{a}}$

Derize Boshoff, $\mathrm{MD}^{\mathrm{b}}$

Benedicte Eyskens, $\mathrm{MD}^{\mathrm{b}}$

Luc Mertens, MD, $\mathrm{PhD}^{\mathrm{b}}$

Marc Gewillig, MD, $\mathrm{PhD}^{\mathrm{b}}$

Steffen Fieuws ${ }^{\mathrm{c}}$

Erik Verbeken, MD, $\mathrm{PhD}^{\mathrm{d}}$

Willem Daenen, MD ${ }^{\mathrm{a}}$
From the Departments of Cardiac Surgery, Pediatric Cardiology, ${ }^{\mathrm{b}}$ Biostatistics, ${ }^{\mathrm{c}}$ and Pathology, ${ }^{\mathrm{d}}$ University Hospital Leuven, Leuven, Belgium.

Read at the Eighty-fourth Annual Meeting of The American Association for Thoracic Surgery, Toronto, Ontario, Canada, April 25-28, 2004.

Received for publication April 22, 2004; revisions received July 23, 2004; accepted for publication Aug 5, 2004.

Address for reprints: Bart Meyns, MD, $\mathrm{PhD}$, Department of Cardiac Surgery, University Hospital Gasthuisberg, Herestraat 49, 3000 Leuven, Belgium (E-mail: Bart. Meyns@uz.kuleuven.ac.be).

J Thorac Cardiovasc Surg 2004;128:834-40 $0022-5223 / \$ 30.00$

Copyright (c) 2004 by The American Association for Thoracic Surgery

doi:10.1016/j.jtcvs.2004.08.015
Objective: We sought to evaluate the incidence and nature of pulmonary stenosis after implantation of the bovine jugular vein graft (Contegra; Medtronic, Inc, Minneapolis, Minn) in the right ventricular outflow tract.

Methods: Between May 2000 and September 2002, 58 Contegra conduits (8-22 $\mathrm{mm})$ were implanted during primary $(\mathrm{n}=27)$ or redo operations $(\mathrm{n}=31)$ in 57 patients, with ages ranging from 2 days to 48 years (mean, 9 years). Indications were truncus arteriosus $(n=16)$, tetralogy of Fallot $(n=28)$, pulmonary replacement in the Ross operation $(\mathrm{n}=10)$, and Rastelli-type repair for double-outlet right ventricle $(\mathrm{n}=4)$. Echocardiography was prospectively performed by a fixed team of investigators during follow-up (mean, $22.7 \pm 10$ months). A peak gradient of greater than $50 \mathrm{~mm} \mathrm{Hg}$ was considered severe stenosis.

Results: Two patients died from Staphylococcus aureus-induced septicemia and enterococcal endocarditis after 12 days and 12 weeks, respectively. One patient died of heart failure caused by endocardial fibroelastosis after 1 year. Freedom from severe stenosis at the distal anastomosis was $91 \% \pm 3 \%$ at 3 months, $68 \% \pm 6 \%$ at 12 months, and $49 \% \pm 8 \%$ at 24 months. The risk of development of stenosis does not change over time. Younger age and its derivatives (graft size and indication) are significantly related to the occurrence of severe stenosis $(P<.0001)$. Seventeen $(29 \%)$ conduits required an endovascular intervention (balloon dilatation or stent). Seven (12\%) conduits were explanted (endocarditis, 2; stenosis, 5). Histologic analysis of the explanted conduits showed excessive proliferation of neointima at the level of the distal anastomosis. Valve regurgitation was observed in $9(16 \%)$ conduits and was always secondary to dilatation in the presence of severe distal stenosis.

Conclusion: The Contegra conduit induces a neointimal proliferation at the level of the pulmonary anastomosis. This leads to a high incidence of severe stenosis at intermediate-term follow-up.

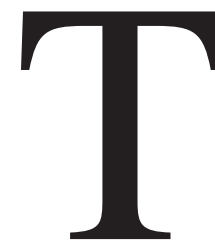

he Contegra conduit (Medtronic, Inc, Minneapolis, Minn) is a heterologous bovine jugular vein graft with a trileaflet venous valve. The conduit is fixed with $0.6 \%$ glutaraldehyde under zero pressure condition. No additional anticalcification treatment is used. Animal trials showed an excellent durability and a low calcification rate. ${ }^{1-4}$ Because this conduit is available in sizes between 12 and $22 \mathrm{~mm}$, it became an ideal candidate for reconstruction of the right ventricular outflow tract in 


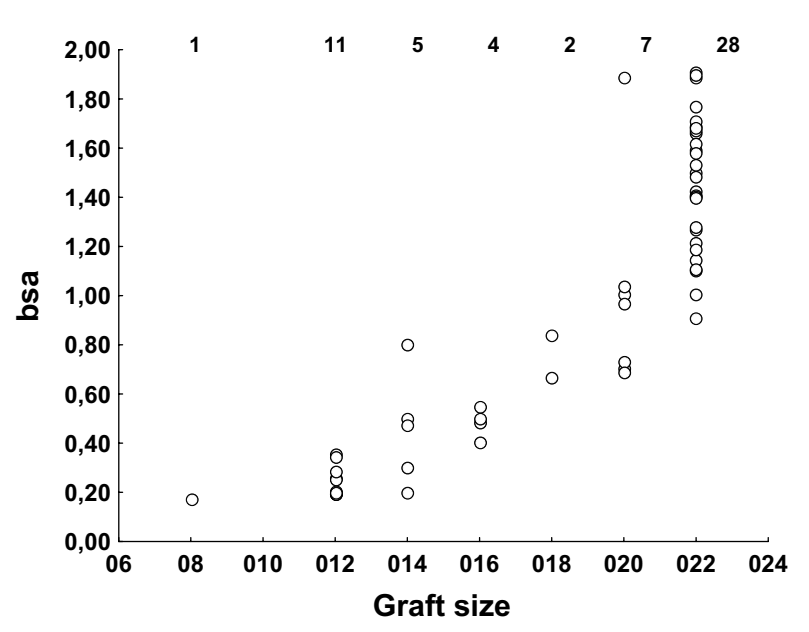

Figure 1. The number of implanted graft sizes. Smaller sizes were implanted in patients with smaller body surface areas (bsa). One valve was bicuspidized to an $8-\mathrm{mm}$ graft.

children with congenital heart disease. Several groups reported encouraging initial clinical results. ${ }^{5-9}$ However, the occurrence of stenosis at the level of the distal anastomosis was reported. ${ }^{10,11} \mathrm{We}$ investigated our patient group to evaluate the incidence and nature of graft stenosis after implantation of this bovine jugular vein graft.

\section{Methods \\ Patients}

Between May 2000 and September 2002, 58 Contegra conduits were implanted in 57 patients to reconstruct the right ventricular outflow tract. Indications were truncus arteriosus $(n=16)$, tetralogy of Fallot $(n=28)$, pulmonary replacement in the Ross operation $(\mathrm{n}=10)$, and Rastelli-type repair for double-outlet right ventricle $(n=4)$. The conduits were placed during a primary operation in 27 patients and during a redo operation in 31 patients. Ages varied between 2 days and 49 years (mean, 9 years).

\section{Surgical Technique}

All implantation procedures were done during support with cardiopulmonary bypass and moderate hypothermia. Antegrade crystalloid cardioplegia was used to arrest the heart. The conduits were rinsed ( 3 times for 5 minutes in normal saline solution). The length of the valve in the Contegra conduit exceeds $2 \mathrm{~cm}$. Therefore the distal part of the conduit was cut at the level of the commissures. The proximal part of the conduit was cut with a redundant anterior flap to construct the hood of the outflow tract. All anastomoses were performed with running polypropylene sutures. The anatomically largest graft size was used. Figure 1 shows the distribution of graft size in relation to body surface area. In one neonate (body surface area, $0.19 \mathrm{~m}^{2}$ ) the Contegra graft was bicuspidized to reduce its size to $8 \mathrm{~mm}$. Transesophageal echocardiography was performed routinely in the operating room and allowed immediate evaluation of the graft.

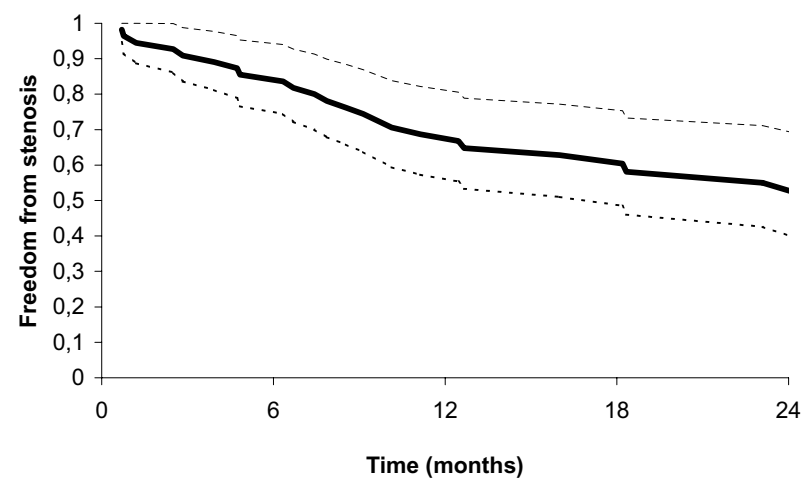

Figure 2. Kaplan-Meier curve ( $95 \%$ confidence limits) of the freedom from severe stenosis at the distal anastomosis (peak gradient, $>50 \mathrm{~mm} \mathrm{Hg}$ ). The hazard of development of pulmonary stenosis does not decrease significantly over time.

\section{TABLE 1. Simple Cox regression}

\begin{tabular}{lcc}
\hline & Hazard ratio & $\boldsymbol{P}$ value \\
\hline Sex & 0.77 & .53 \\
Diagnosis & & .03 \\
$\quad$ Rastelli vs truncus & & .011 \\
Primary operation & 2.95 & .009 \\
Younger age & 0.865 & $<.0001$ \\
Smaller graft size & 0.818 & $<.0001$ \\
\hline
\end{tabular}

In a multiple regression only age or size remains significant.

\section{Follow-up}

Patients did not receive aspirin or any other antiaggregant or anticoagulant medication. Postoperative echocardiography was performed by a fixed team of 4 investigators. All patients had a predischarge echocardiographic evaluation and were followed, according to the study protocol, at 1, 3, 6, and 12 months after the operation and yearly thereafter. In case of pathologic findings (like an increased gradient), the patients were asked to return earlier. An instantaneous peak gradient of greater than $50 \mathrm{~mm} \mathrm{Hg}$ was considered severe stenosis. A pulmonary valve regurgitation grade 3 or 4 or more was considered significant. Grading of the pulmonary valve insufficiency was based on the following echocardiographic findings: a regurgitation jet restricted to the right ventricular outflow tract (grade 1), a jet reaching into the ventricular body (grade 2 ), backflow starting from the level of the pulmonary artery bifurcation (grade 3), and backflow starting from the peripheral pulmonary artery branches (grade 4). One patient was lost to follow-up after 1 month. The mean follow-up was $22.7 \pm 10$ months.

\section{Analysis of Data}

The occurrence of pulmonary stenosis is presented with a KaplanMeier survival curve with $95 \%$ confidence limits. Cox regressions have been used to verify the relationship between different covariates and pulmonary stenosis. The reported $P$ values are obtained with likelihood ratio tests. A Weibull model has been used to verify the shape of the hazard function. All analyses have been performed with the statistical package SAS (version 8.2). 


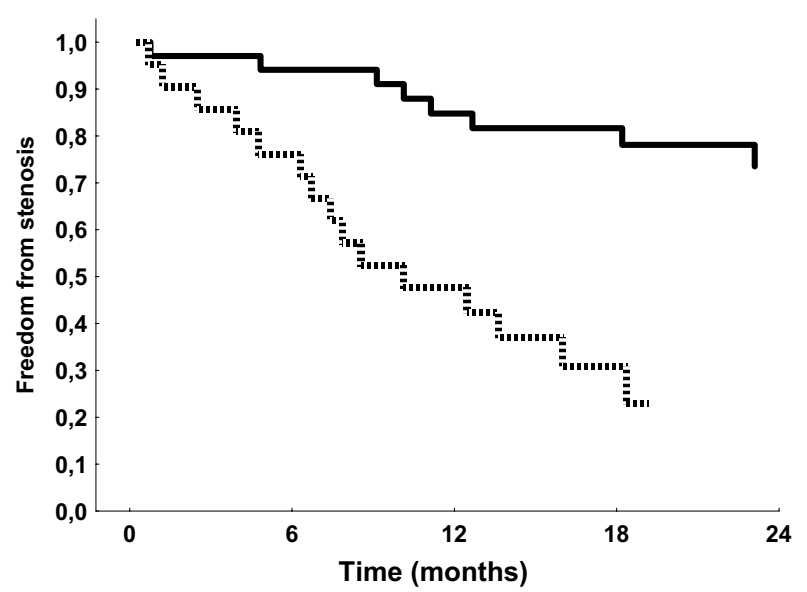

Figure 3. Kaplan-Meier curve of the freedom from severe stenosis at the distal anastomosis (peak gradient, $>50 \mathrm{~mm} \mathrm{Hg}$ ) for the small graft sizes (interrupted line) and the large graft sizes (full line). In small sizes (graft size, $<20 \mathrm{~mm}$ ) hemodynamic gradients develop more quickly $(P=.0007)$. However, in the adult sizes (graft sizes 20 and $22 \mathrm{~mm}$ ) 15\% of the patients had stenosis after 1 year.

\section{Results}

\section{Patient Outcome}

Two patients died from Staphylococcus aureus-induced septicemia and enterococcal endocarditis after 12 days and 12 weeks, respectively. One patient died after 12 months of heart failure (patient with endocardial fibroelastosis). The Contegra graft in this patient functioned well, without stenosis or valve regurgitation. Three $(5 \%)$ patients were given diagnoses of endocarditis. One died, and the 2 others were cured through the removal of the conduit and the placement of a homograft.

\section{Contegra Function}

All observed stenoses were located at the distal anastomosis. Freedom from severe stenosis at the distal anastomosis was $91 \% \pm 3 \%$ at 3 months, $68 \% \pm 6 \%$ at 12 months, and $49 \% \pm 8 \%$ at 24 months (Figure 2). A Weibull model was fitted to obtain an idea of the shape of the hazard function. The estimated scale parameter equals 1.12 (95\% confidence limits, 0.78-1.59), which indicates that there is no evidence for a nonconstant hazard.

Simple Cox regression indicates primary repair, younger age, and smaller graft size as significantly related to the occurrence of distal graft stenosis (Table 1). For the effect of diagnosis, only the difference between truncus arteriosus and Rastelli repair was significant. However, the group of patients undergoing Rastelli repair was small and contained no events. In a multiple regression framework, only age or graft size remained significant. The correlation between younger age and smaller graft size is very high (Spearman correlation, $=0.89$ ).
Although graft size is significantly related to the occurrence of stenosis, large graft sizes also resulted in a high incidence of stenosis. At 1 year of follow-up, $15 \%$ of patients with an adult graft size (size 20 or 22) already had a severe stenosis (Figure 3) at the distal anastomosis. Stenosis occurred in ten of twelve 12-mm grafts, three of five 14-mm grafts, two of four $16-\mathrm{mm}$ grafts, none of two 18 -mm grafts, three of seven 20 -mm grafts, and seven of twenty-eight 22-mm grafts.

Seventeen (29\%) conduits required an endovascular intervention (balloon dilation or stent). Seven (12\%) conduits were explanted ( 2 because of endocarditis and 5 because of stenosis). The 5 conduits explanted because of stenosis had peak gradients of between 70 and $80 \mathrm{~mm} \mathrm{Hg}$, despite balloon dilation and stenting.

Pulmonary valve regurgitation $(\geq 3 / 4)$ was diagnosed in $9(16 \%)$ patients. In all cases this was secondary to a dilation of the conduit caused by severe distal stenosis.

\section{Pathologic Findings}

The 2 conduits explanted for endocarditis were excluded for further analysis of the distal anastomosis. The 5 other grafts were explanted after $12,16,19,32$, and 32 months, respectively.

All conduits showed preserved wall integrity. The leaflets were intact and pliable. Low-grade calcification was found in the wall of 3 conduits. All distal anastomoses showed an excessive amount of neointima composed of spindle cells more or less parallel oriented to the luminal surface (Figures 4 and 5). There were no inflammatory cells, newly formed vessels, or iron-loaded macrophages (siderophages). As expected, the suture holes were surrounded by a sharply demarcated foreign-body reaction in the Contegra conduit, as in the pulmonary artery.

\section{Discussion}

The reconstruction of the right ventricular outflow tract is an essential part of the treatment of congenital heart disease. Clearly, in the growing child several reoperations seem inevitable to adjust the graft size. Occurrences of arrhythmia, dilation of the right ventricle, or both are indications for replacement of an insufficient outflow graft. On the basis of the increasing performance of cardiac surgical teams, some surgeons suggest replacing an inefficient graft to avoid damage to the right ventricular muscle. ${ }^{12}$ The gold standard has been set with the use of the homograft. The reported freedom from reoperation with homografts is close to $80 \%$ at 10 years for the adult sizes. ${ }^{13,14}$ When implanted in neonates, $75 \%$ have to be replaced within 5 years. ${ }^{15,16}$ The Contegra graft appears to be an ideal substitute. The valve is readily available in a wide range of sizes, and it has a nice long conduit with superior suturing and tailoring capacities. Since its clinical introduction in 1999, several 


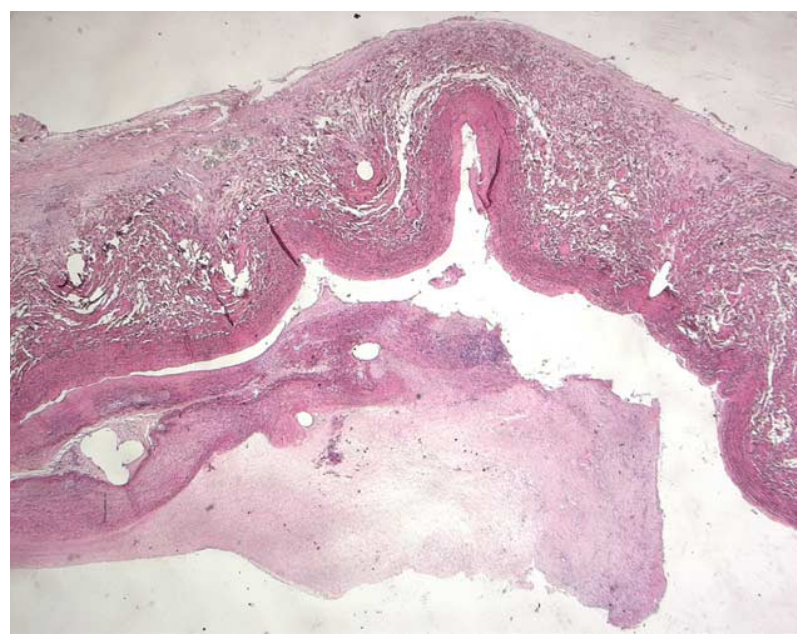

Figure 4. Conduit explanted after 12 months because of severe stenosis (elastic van Gieson staining 12.5×): transverse section through the distal anastomosis showing, from top to bottom, the normal native architecture of the pulmonary artery, the jugular vein graft, and, at the bottom, a thick neointima. Note the suture holes, with some surrounding foreign-body reaction confined to the arterial and venous walls, respectively.

groups have adapted it with enthusiasm. ${ }^{5-9}$ Animal experiments with this conduit were encouraging. Herijgers and colleagues ${ }^{1}$ showed a well-preserved valve function and a low calcification rate of Contegra grafts when implanted in the pulmonary position in sheep for 5 months. Although the graft has no specific anticalcification treatment, only minimal calcification was noted. Ichikawa and coworkers ${ }^{2}$ described excellent results in adult dogs after 1 year of implantation with bovine jugular vein grafts fixed with a hydrophilic polyepoxy compound. Scavo and associates ${ }^{4}$ implanted glutaraldehyde-preserved bovine jugular vein grafts in 31 dogs (valved and nonvalved), with a mean follow-up of 237 days. The grafts showed a low calcification rate and excellent hemodynamic performance.

Earlier reports in the recent literature mentioned the occasional problems with high-grade stenosis after implantation of the Contegra graft. Boudjemline and colleagues ${ }^{10}$ reported the occurrence of an aneurysm of the right ventricular outflow tract secondary to a tight stenosis of the distal anastomosis of a Contegra graft. Kadner and coworkers ${ }^{11}$ reported the formation of stenotic membranes at the distal anastomosis, requiring graft removal in 2 of 67 implants. In a series of 27 implants, Brown and Darragh ${ }^{9}$ reported the occurrence of a significant obstruction at the distal anastomosis in a child 18 months after implantation. Breymann and associates ${ }^{6}$ comment, in their report on 71 implants, on the development of a significant gradient in 6 patients just distal from the conduit. However, the reported mediumterm durability was equivalent to that of homografts and superior to that of xenografts.

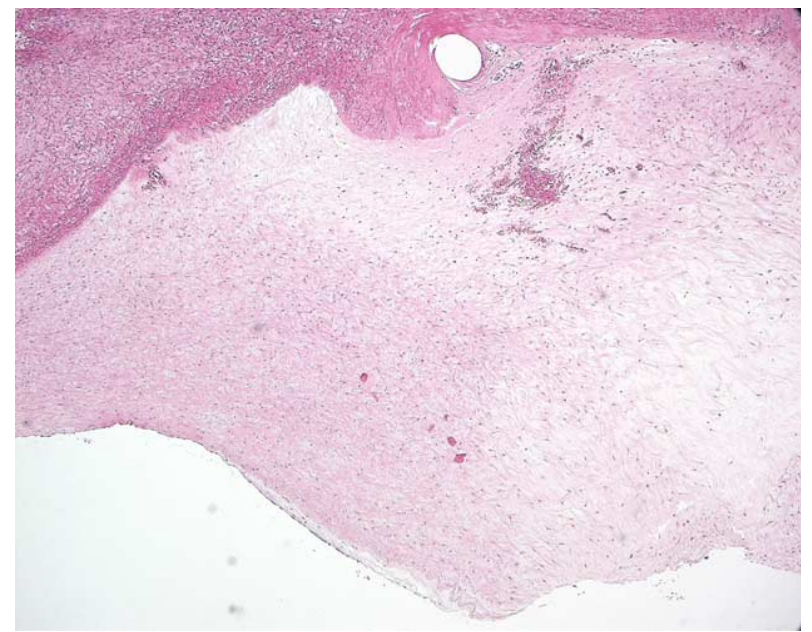

Figure 5. Detail of the neointima in a conduit explanted after 12 months because of severe stenosis (elastic van Gieson staining $50 \times)$. The neointima is composed of uniformly distributed spindle cells, without neovascularization or inflammation. Concentrically oriented histiocytes surround the suture hole. The latter reaction is sharply demarcated from the neointima.

We observed an increasing rate of severe stenosis localized at the level of the distal anastomosis. The hazard of creating such a stenosis did not decrease significantly in the observed 2 years of follow-up, suggesting a chronic trigger. The pathologic findings in the resected specimens were consistent. There is an excessive peel formation at the distal anastomosis. There is no active inflammatory reaction, the valve leaflets remain pliable, the integrity of the Contegra graft remains intact, and there are no signs of rapid calcification. This peel formation is very similar to the neointima found in vascular grafts. Morphologically, this process seems unrelated to a coincidental complication, such as thrombosis or infection. An organizing thrombus would result in granulation tissue with newly formed vessels or with the presence of siderophages originating from the digestion of erythrocytes. Obviously the neointima is unrelated to the suture itself, from which it is sharply demarcated.

It is logical to assume that such a peel is formed to create a smooth inner lining of small wall irregularities. It remains puzzling why this healing process tends to overreact in the Contegra graft. A specific feature of this Contegra graft is its pliability. In contrast to homografts, the Contegra graft consists of bovine jugular vein with a more compliant wall. Chronic movement of the Contegra wall at the level of the anastomosis could be an ongoing local trigger for peel formation.

The similarity with the findings of Ishizaka and coworkers ${ }^{17}$ in their experience with the Shelhigh No-react (ShelhighBioMitral, Millburn, NJ) graft is striking. After implantation of 
the Shelhigh graft in 24 small children, Ishizaka and coworkers found mild-to-severe conduit stenosis, regurgitation, or both in $84 \%$. The typical finding of the explanted conduits was prominent intimal peel formation at the distal anastomosis without calcification. Boudjemline and associates ${ }^{18}$ suggest that the underlying cause of this similar phenomenon might be due to an immunologic reaction. However, in the reported Shelhigh graft failures, as well as in our series with the Contegra graft, there is little histologic evidence of immunologic activity.

In contrast to other series, none of our patients received aspirin or any other antiaggregant. Aspirin plays a protective role for the endothelium and influences neointima formation. ${ }^{19,20}$ In view of our current findings, it appears logical to routinely start aspirin therapy after the implantation of this graft.

Clearly, the peel formation quickly creates hemodynamic disturbances in small graft sizes. However, with ongoing follow-up, we also observed severe stenoses in our adult Contegra sizes. At 1 year, $15 \%$ of our adult patients receiving a Contegra graft already had a significant stenosis. These results urged us to stop the use of this graft.

\section{References}

1. Herijgers P, Ozaki S, Verbeken E, Van Lommel A, Meuris B, Lesaffre E, et al. Valved jugular vein segments for right ventricular outflow tract reconstruction in young sheep. J Thorac Cardiovasc Surg. 2002; 124:798-805.

2. Ichikawa Y, Noishiki Y, Kosuge T, Yamamoto K, Kondo J, Matsumoto A. Use of bovine jugular vein graft with natural valve for right ventricular outflow tract reconstruction: a one-year animal study. J Thorac Cardiovasc Surg. 1997;114:224-33.

3. Bonhoeffer P, Boudjemline Y, Saliba Z, Hausse AO, Aggoun Y, Bonnet $\mathrm{D}$, et al. Transcatheter implantation of a bovine valve in pulmonary position. Circulation. 2000;102:813-6.

4. Scavo VA, Turrentine MW, Aufiero TX, Sharp TG, Brown JW. Valved bovine jugular venous conduits for right ventricular to pulmonary artery reconstruction. ASAIO J. 1999;45:482-7.

5. Corno AF, Hurni M, Griffin H, Galal OM, Payot M, Sekarski N, et al. Bovine jugular vein as right ventricle-to-pulmonary artery valve conduit. J Heart Valve Dis. 2002;11:242-7.

6. Breymann T, Thies WR, Boethig D, Goerg R, Blanz U, Koerfer R. Bovine valved venous xenografts for RVOT reconstruction: results after 71 implantations. Eur J Cardiothorac Surg. 2002;21:703-10.

7. Carrel T, Berdat P, Pavlovic M, Pfammatter JP. The bovine jugular vein: a totally integrated valved conduit to repair right ventricular outflow. J Heart Valve Dis. 2002;11:552-6.

8. Bove T, Demanet H, Wauthy P, Goldstein JP, Dessy H, Viart P, et al. Early results of valved bovine jugular vein conduit versus bicuspid homograft for right ventricular outflow tract reconstruction. Ann Thorac Surg. 2002;74:536-41.

9. Brown JW, Darragh RK. Valved bovine jugular vein conduits for right ventricular outflow tract reconstruction: an attractive and less expensive alternative to pulmonary homografts. Oral communication. Presented at the 83rd Annual Meeting of The American Association for Thoracic Surgery. Boston (MA): May 4-7, 2003.

10. Boudjemline Y, Bonnet D, Agnoletti G, Vouhé P. Aneurysm of the right ventricular outflow following bovine valved venous conduit insertion. Eur J Cardiothorac Surg. 2003;23:122-4.

11. Kadner A, Dave H, Stallmach T, Turina M, Prêtre R. Formation of a stenotic fibrotic membrane at the distal anastomosis of bovine jugular vein grafts (Contegra) after right ventricular outflow tract reconstruction. J Thorac Cardiovasc Surg. 2004;127:285-6.
12. Hanley FL. Management of the congenitally abnormal right ventricular outflow tract: what is the right approach? J Thorac Cardiovasc Surg. 2000;119:1-3.

13. Daenen W, Gewillig M. Factors influencing medium-term results of right-sided cryopreserved homografts. J Heart Valve Dis. 1997;6:347-54.

14. Bielefeld MR, Bishop DA, Campbell DN, Mitchell MB, Grover FL, Clarke DR. Reoperative homograft right ventricular outflow tract reconstruction. Ann Thorac Surg. 2001;71:482-8.

15. Forbess JM, Shah AS, St Louis JD, Jaggers JJ, Ungerleider RM. Cryopreserved homografts in the pulmonary position: determinants of durability. Ann Thorac Surg. 2001;71:54-60.

16. Homann M, Haehnel JC, Mendler N, Paek SU, Holper K, Meisner H, et al. Reconstruction of the RVOT with valved biological conduits: 25 years experience with allografts and xenografts. Eur J Cardiothorac Surg. 2000;17:624-30.

17. Ishizaka T, Ohye RG, Goldberg CS, Ramsburg SR, Suzuki T, Devaney EJ, et al. Premature failure of the small-sized Shelhigh No-React porcine pulmonary valve conduit model NR-4000. Eur J Cardiothorac Surg. 2003;23:715-8.

18. Boudjemline Y, Beyler C, Bonnet D, Sidi D. Surprising outcome similarities between Contegra bovine jugular vein conduit and Shelhigh No-React porcine pulmonary valve conduit: role of immunological reaction. Eur J Cardiothorac Surg. 2003;24:850-1.

19. Torsney E, Mayr U, Zou Y, Thompson WD, Hu Y, Xu Q. Thrombosis and neointima formation in vein grafts are inhibited by locally applied aspirin through endothelial protection. Circ Res. 2004;94:1466-73.

20. Volker W, Faber V. Aspirin reduces the growth of medial and neointimal thickenings in balloon-injured rat carotid arteries. Stroke. 1990; 21:44-5.

\section{Discussion}

Dr John W. Brown (Indianapolis, Ind). Before I comment on this paper, I need to disclose that I serve on the Medtronic scientific advisory board for cardiac valves.

I want to congratulate Dr Van Garsse, Professor Daenen, and their colleagues for their very fine presentation and for providing me a copy of their manuscript well in advance of this meeting. By doing so, they gave me the opportunity to review our own experience with the Contegra graft and the results of our pulmonary homografts during a 5-year period, during which we have placed 47 Contegra grafts. I also was able to review the 8 published manuscripts that are in the literature for the Contegra graft.

Although several investigators have reported a small incidence of supravalvular pulmonary stenosis with the Contegra graft, Drs Van Garsse and Daenen's incidence of supravalvular pulmonary stenosis is 8- to 10-fold that of the combined experience of the rest of the published literature.

In our 47 patients we have encountered supravalvular pulmonary stenosis in 3 patients, most of which we thought was due to technical errors on our part. In 2 of these patients, the distal pulmonary stenosis was easily remedied by balloon angioplasty. The third patient did not yield to balloon angioplasty, and the distal anastomosis was patched with pericardium. All 47 patients with Contegra grafts still have their original grafts, and no patient has a gradient of greater than $30 \mathrm{~mm} \mathrm{Hg}$.

My review of the 8 published reports of 314 patients shows that the incidence of supravalvular pulmonary stenosis with a gradient of only $30 \mathrm{~mm} \mathrm{Hg}$ is $6 \%$. The $50 \%$ incidence of a gradient of greater than $50 \mathrm{~mm} \mathrm{Hg}$ is outstanding.

The mean age of your patients was 9 years versus 6 years in our series. You did not use aspirin or anticoagulants postoperatively, but you commonly used tissue glue on the distal anastomosis. We have always, with both our pulmonary homografts and our Con- 
tegra grafts, used minidose aspirin and a short course of lowmolecular-weight heparin because all of our children have central lines, and we know that central lines produce venous obstruction.

I would conclude that there are 3 plausible causes for the high incidence of stenosis seen in your center and the low incidence in our center and the rest of the centers reporting results with a Contegra graft.

One, it has to be patient-prosthesis mismatch.

Two, there might be technical problems, either pursestringing the distal anastomosis or the conduit is put in slightly too long, and therefore it kinks at the distal anastomosis.

The third point is that it might well be due to the lack of anticoagulation, which produces a thrombosis that occurs in the early postoperative period and then blanches out and gives you the impression that you have a neointimal peel.

You have reported your results with a Contegra graft and have abandoned its use. My question, because you admit that the Contegra is a beautiful conduit in your manuscript and that the only problem is distal pulmonary artery stenosis, is as follows: Would you consider either altering your surgical technique or adding a short course of antiplatelet agents or anticoagulants rather than resorting to a pulmonary homograft that has demonstrated limited durability and the lack of valve function within a few months after implantation?

Dr Van Garsse. Thank you very much for your comments.

We know that we have a high incidence of stenosis at the distal anastomosis. Therefore we looked very closely at these stenoses, which resulted in the findings we presented today. All the patients presenting with a stenosis underwent an angiography, and all of them had the stenosis really at the distal anastomosis.

We do not believe that a technical problem is the reason for these stenoses because we perioperatively perform an echocardiography, and at that time, we never see that problem. Moreover, the hazards of stenosis development are constant; in the beginning, we do not see stenosis, but it comes over time.

Concerning your remark on anticoagulation, we do not find any evidence of thrombosis in the neointima according to the findings of our pathologists. We think that pliability of the graft at the distal anastomosis might play an important role in the development of the distal formation of neointima.

Dr Hani K. Najm (Riyadh, Saudi Arabia). We have also used this conduit for approximately 45 patients. We have had a similar experience to what Dr Brown has actually mentioned-almost identical to that seen in his series-and we found that one patient, early in our experience, came back with peripheral pulmonary artery stenosis, which was not present or related to the surgical procedure (ie, was not present in the early postoperative echocardiography). This prompted me to think that there might be something other than the technical reasons at work.

This conduit is quite long. It is around 8 to $10 \mathrm{~cm}$. It is quite soft and pliable, and if you rinse it in the usual fashion (ie, just putting in some washing solution in the standard rinsing technique), no solution will get inside the valved conduit, especially if you always cut the segment before and after the valve. The valve sits in the middle. Therefore my hypothesis is that most likely you can leave glutaraldehyde on that valve. And when you suture that to the pulmonary arteries, you can transfer some of that glutaraldehyde to the pulmonary arteries, and that could fix the site of anastomosis and might trigger intimal hyperplasia, which can be the reason why you could have distal stenosis.

Since then, I have totally changed the way we rinse this conduit. We choose the conduit right at the beginning of the procedure. We put it in for whatever-half an hour or $45 \mathrm{~min}$ utes-until we need it. I cut it and rinse it again after I cut it to make sure that it is thoroughly rinsed from the inside.

Was this your experience, or have you changed your techniques of rinsing?

Dr Van Garsse. Thank you for that comment as well. Well, we also rinse the conduit in saline solution 3 times for 5 minutes and leave it in the saline thereafter. We rinse it in such a way that the saline is going through the valve. We do not rinse it after cutting the conduit. This might be a good idea.

Dr Michal A. Wojtalik (Poznan, Poland). I was one of the main investigators of the Contegra graft in clinical study. My experience is based on 40 cases, and the long-term follow-up is about 5 years. We have quite the opposite experience to your experience. Therefore we are very enthusiastic about this graft.

Still, during our study, we discussed problems that appeared in some patients. One of them was distal pulmonary stenosis. The rinsing process was stressed as very important. For 3 years, we just overrinse the graft, even cutting earlier the excess of the distal part and rinsing the crosscut too. It seems to help avoid this complication.

The second problem that we discussed was immune response that is very likely in a foreign tissue implant. My group did the immune study in a group of 20 patients. The results were published in Interactive Cardiovascular and Thoracic Surgery (2003;2:2738 ). We found that there was an important difference in B-cell count between the control group and the study group half a year after implantation of the Contegra graft and in T-cell count after 1 year. Therefore I think that immune response might play a role in the development of relatively rare complications after Contegra implantations. That has also been proved by few obtained specimens from explanted conduits.

Dr Van Garsse. Thank you. This is a very interesting theory, but we could not confirm it according to the findings of the pathologists in our study.

Dr Carlos J. Troconis (Caracas, Venezuela). Years ago, we had similar problems of supravalvular pulmonary stenosis at the distal anastomosis when using bovine pericardium conduits, most of which we thought were due to technical errors, and therefore we modified it as we did a "fish-mouth" opening and performed an oblique anastomosis, avoiding pursestringing, and extending it toward the left side sometimes might prevent it from happening.

Also, we did use aspirin for long periods to avoid thrombosis, as well as anti-inflammatory therapy to prevent chronic rejections.

Finally, I would not discourage you in your work because I think it is a good conduit to be used.

Dr Van Garsse. Thank you.

Dr Gary K. Lofland (Kansas City, Mo). I have not used this graft, and therefore I have no conflicts to disclose. I happen to be rather intensely allergic to glutaraldehyde, and therefore your study would suggest that there is a problem at the bioprosthetic interface between the graft and the native pulmonary tissue. Years ago, John Brown and his colleagues, in really elegant studies, demonstrated early degeneration of homografts if they were inter- 
posed with Dacron, as opposed to expanded polytetrafluoroethylene.

Therefore my question is a purely hypothetical one directed at both the authors and Dr Brown. If this bioprosthetic interface were eliminated by interposition of a short segment of polytetrafluoroethylene, which appears to be inert in these situations, could these problems be ameliorated?

Dr Van Garsse. Well, we do not think glutaraldehyde fixation is responsible for these distal peel formations. Our theory is that it is because of the pliability of the graft at the distal anastomosis, which induces a chronic repetitive trauma to the neointima, causing an excessive neointimal proliferation.

Are you suggesting some kind of reinforcement of the distal anastomosis?

Dr Lofland. My thought is just to eliminate that bioprosthetic interface, and we know that problems can occur when you interface materials with biologic structures. Expanded polytetrafluoroethylene just seems to be relatively inert and could conceivably stent the Contegra graft open. It is a purely hypothetical question.

Dr Van Garsse. Thank you. 